\title{
The far Barcoo where they eat nardoo
}

To carry me westward ho, my boys, that's where the cattle stray,

On the far Barcoo where they eat nardoo. a thousand mile away. ${ }^{1}$

SIR - Earl and McCleary ${ }^{2}$ provide a perceptive explanation for the illness which, together with starvation, caused the deaths of Burke and Wills. It is a convincing proposal that eating nardoo, prepared without leaching, resulted in excessive thiaminase ingestion and the development of peripheral neuropathy in the explorers. King, the survivor of the expedition, may well have had additional symptoms of cerebral beriberi at the time of his rescue.

The authors are wrong in equating 'Barcoo rot' with scurvy. Barcoo rot is an infective dermatosis, caused by diphtheroid organisms, similar to Veld sore or desert sore $^{3}$. Susceptibility to the infection may be increased by vitamin deficiency, but the deficiency is predominantly niacin deficiency, resulting in pellagra, rather than lack of ascorbic acid. Albert Gaston ${ }^{+}$ described the disease in miners from Coolgardie (Western Australia): "By continually living on preserved food with a lack of vegetables, the miners' health began to suffer, and a great number of them suffered from Barcoo rot. The skin of the hands and arms became brittle and tender and the slightest scratch soon became a dry hard sore which refused to heal." A more detailed clinical description is given in ref. 3 .

Another, entirely different disease of the same period is referred to as Barcoo fever, the symptoms of which were severe nausea, vomiting, often associated with constipation, fever, myalgia, lethargy and possible death. It is probable that this disease was due to ingestion of water containing toxins of cyanobacteria ${ }^{5}$, which were present and produced toxicity in some water sources well before the development of European settlement".

The members of the rear party, who perished on their delayed and futile attempt to move up to the base camp on Cooper Creek, were not suffering from vitamin deficiency and had not eaten nardoo. They died of inanition camped beside the few remaining sources of water between the Darling River and Cooper Creek. Their symptoms were those of hepatotoxicity, and the probable cause was cyanobacterial toxins from contaminated water'. They died of 'Barcoo fever', although the disease was probably not known and certainly not named at the time.

The Barcoo River rises in central Queensland and flows south and west for $500 \mathrm{~km}$ to join the Thomson River to form the waters of Coopers Creek, beside which Burke and Wills died. They and the creek will remain in Australian history; the Barcoo and nardoo are part of that account.

\section{John Hayman}

Department of Pathology,

Box Hill Hospital,

Box Hill, Melbourne,

Victoria 3128, Australia 1. Anon. The Penguin Book of Australian Ballads (ed. Ward,
R.) $130-131$ (Penguin Books, Melbourne, 1964).
2. Earl, J. W. \& McCleary, B. V. Nature 368,683-684 (1994).
3. Cliento. R. Tropical Diseases in Australia (2nd edn),
344-347 (W. R. Smith \& Paterson. Brisbane. 1942).
4. Gaston, A. Coolgardie Gold. 143 (A. H. Stockwell, London,
c.1937).
5. Hayman, J. Med. J. Aust. 157, 794-796 (1992).
6. Francis G. Nature 18. 11-12 (1878).
7. Faiconer, I. R., Beresford A. M., \& Runnegar M. T. C. Med J.
Aust. 1. 511 -514 (1983).

\section{Notreason}

SIR - "Insubstantial charges of treason" (Nature 368, 779; 1994) brings needed scepticism to charges that Enrico Fermi. Robert Oppenheimer, Leo Szilard and others passed nuclear weapons secrets to the Soviet Union. At the same time, however, it perpetuates a common misconception by repeated use of the word "treason" to describe the alleged spying. The US Constitution specifically defines treason as giving aid and comfort to enemies of the United States. The Soviet Union at the time of the Manhattan Project was an ally of the United States and Great Britain in their war against Nazi Germany. The alleged actions of Fermi $e t$ $a l$. are serious enough to be called by their proper name - espionage - without using an inflammatory term that distorts the historical record.

\section{Curt Covey}

Lawrence Livermore National Laboratory, Global Climate Research Division,

Mail Code L-264,

POBox 808,

Livermore, California 50550, USA

\section{Return of the native}

Sir - As a Mexican scientist I should like to comment on the Mondragón syndrome of bad timing (Nature 368, 793; 1994).

Like Alfonso Mondragón, I had the opportunity to pursue postgraduate studies as well as postdoctoral positions in Europe and the United States with possibilities of staying in the United States. But I was convinced that I had to return; I learned from some teachers how science could be done with low resources and the importance of building a scientific community in this developing country. In 1980 I acquired a research associate position at the Instituto de Investigaciones Biomèdicas in UNAM. The decade of the 1980 s was very hard indeed, especially for young scientists starting their careers; one needed to ask what experiments could be done with existing resources and not the other way around, and equipment and reagents had to be shared. Much time was (and still is) devoted to teaching and bureaucracy. Not only did people not want to return to Mexico, but many already here left.

We helped to create the Center of Genetic Engineering (now the Institute of Biotechnology) and, looking back, although it has been hard and demanding, we feel satisfied. The institute is productive, we have nurtured several young scientists and although our scientific papers might not be as many as if we had not returned they are equally relevant.

What would have happened if all young scientists in the 1980 s had left? In the words of a former US president they asked "not what can the country do for me but what can I do for my country?"

Yes, we do need more scientists but only those willing to work hard to overcome existing problems and not those who feel they deserve special privileges just because they 'sacrifice' themselves by returning.

Patricia Joseph-Brayo

Instituto de Biotecnología,

Universidad Nacional

Autónoma de México,

Apdo 510-3, Cuernavaca,

Morelos 62271, Mexico

\section{Animal research}

SiR - William Dantzler et al. and Susan Paris (Nature 369, 9-10; 1994) rule out any discussions about the use of animals in research with those who pursue abolition, preferring instead to discuss its continuation only through espousing a policy of humane care.

While the ultimate 'goal' of Advocates for Animals remains the total abolition of animals used in research, the society does at the same time seek humane care for animals used in laboratories today. In Britain such a stance has not prevented Advocates for Animals from taking part in meaningful and 'rational' discussions nor hindered it from finding 'common ground' with the scientific community. Only through dialogue, debate and respect for each other's views will this whole controversial issue of the use of animals in research move forward.

\section{Les Ward}

Advocates for Animals, 10 Queensferry Street, Edinburgh EH2 4PG, UK

Letters submitted for Correspondence should be typed, double-spaced, on one side of the paper only. 